\title{
DETECÇÃO HISTOPATOLÓGICA DE CISTOS DE Sarcocystis spp. EM MUSCULATURA DE UM QUATI (Nasua nasua) - RELATO DE CASO
}

(Histological detection of Sarcocystis spp. cysts in the musculature of a Coati (Nasua nasua) - Case Report)

Vinicius Dahm, Arthur Colombari Cheng, Karim Cristhine Pase Montagnini, Juliana Das Chagas Goulart, Carolina Fontana, Hidemi Kelly Nishimura, Ronaldo José Piccoli, Aline de Marco Viott

Universidade Federal do Paraná, Palotina, Paraná, Brasil.

*Correspondência: alinedemarco@yahoo.com.br

RESUMO: Sarcocystis spp. são protozoários do filo Apicomplexa que acometem diversas espécies, incluindo o homem, e dependendo da espécie do parasito em questão, os seres humanos podem atuar tanto como hospedeiros intermediários quanto definitivos. Quanto aos hospedeiros intermediários, os animais silvestres como primatas e mamíferos herbívoros se destacam, apresentando cistos do protozoário em sua musculatura. Carnívoros e onívoros atuam como hospedeiros definitivos e contaminam-se ingerindo os cistos presentes na musculatura de animais infectados (FAYER; ESPOSITO; DUBEY, 2015). A espécie S. neurona possui grande importância na equideocultura, uma vez que equinos podem desenvolver uma neuropatia conhecida como mieloencefalite protozoária equina, tendo como principal fonte de infecção o Gambá-de-orelhabranca (Didelphis albiventris), principal hospedeiro definitivo desta espécie (ESTEVAM, 2017). O Quati-de-cauda-anelada (Nasua nasua), devido a sua proximidade com os gambás, pode se contaminar ingerindo os oocistos presentes nas fezes dos marsupiais, podendo atuar como hospedeiros intermediários da doença. Diante disso, relata-se um caso de Sarcocystis spp. em Quati-de-cauda-anelada diagnosticado no Laboratório de Patologia Veterinária (LPV) da Universidade Federal do Paraná - Setor Palotina. Um quati, fêmea, foi atendido no Hospital Veterinário da UFPR, Setor Palotina, com histórico de atropelamento seguido de óbito, sendo encaminhado ao LPV para exame necroscópico. Na macroscopia, observou-se áreas multifocais de moderada hemorragia em musculatura de membro pélvico esquerdo decorrentes do trauma. $\mathrm{Na}$ microscopia, observou-se moderada quantidade de estruturas parasitárias císticas de tamanhos variáveis, com uma cápsula eosinofílica contendo inúmeros esporozoítos, compatíveis com cistos de Sarcocystis spp. Próximo aos cistos parasitários, notou-se moderado aumento da eosinofilia sarcoplasmática e perda das estriações (degeneração). Por se tratar de uma enfermidade que pode acometer os seres humanos, a detecção do agente em animais silvestres e sinantrópicos deve ser levada em consideração para a implementação de medidas sanitárias e de educação preventivas, visto que este agente pode ser transmitido de maneira indireta pelo consumo de água e alimentos contaminados com oocistos, bem como a ingestão de carnes (principalmente de caça) com a presença de cistos na musculatura. Além disso, a doença possui importância econômica, principalmente na criação de equinos, podendo levar à morte dos animais. Diante disso, pode-se concluir que a histopatologia foi de suma importância para a detecção do protozoário, e a presença do agente pode indicar uma contaminação ambiental.

Palavras-chave: animais silvestres; hospedeiro intermediário; zoonose

\section{Referências}

FAYER, R.; ESPOSITO, D. H.; DUBEY, J. P. Human infections with Sarcocystis species. Clinical Microbiology Reviews, v. 28, n. 2, p. 295-311, 1 abr. 2015.

ESTEVAM, L. G, T de M. Avaliação de hemoparasitos e ectoparasitos em Quatis (Procyonidae: Nasua nasua) no parque das mangabeiras, Belo Horizonte, Minas Gerais. Dissertação (Mestrado em Parasitologia) - Universidade Federal de Minas Gerais, Belo Horizonte, 2017. 